Check for updates

\section{London}

Cite this as: BMJ 2021;372:n491 http://dx.doi.org/10.1136/bmj.n491 Published: 18 February 2021

\title{
Covid-19: Infections in England fall by two thirds since January
}

Jacqui Wise

A "strong decline" has been seen in the prevalence of SARS-CoV-2 in England among the general population five to six weeks into lockdown, show the latest data from the Real-time Assessment of Community Transmission (React-1) study. ${ }^{1}$

Covid-19 infections in England fell by two thirds from $1.57 \%$ in early January to $0.51 \%$ in early to mid-February, in the ninth round of the study carried out by Imperial College London. Prevalence remains high, however, with around 1 in 196 people testing positive-similar to late September 2020. The researchers estimate that the national $\mathrm{R}$ number for England is 0.72 and that infections are halving every 15 days.

The prevalence of infection has dropped across all ages at a similar rate, which the researchers say suggests that the downward trends are due to reduced social interaction during lockdown rather than the impact of vaccination.

The highest number of infections is among 18-24 year olds at $0.89 \%$ (down from $2.44 \%$ ) and in children aged 5-12 at $0.86 \%$ (down from $1.59 \%$ ). Over 65 s were the least likely to test positive (o.3\%, down from $0.93 \%)$.

The snapshot survey also found that prevalence was highest in people of Asian ethnicity and people living in larger households or in deprived neighbourhoods. Healthcare workers and care home workers were more likely to test positive than other workers.

Infections have fallen around the country, but the decline was largest in London, the south east, and the West Midlands, where prevalence fell by around $80 \%$. The declines were smaller in northern regions of the country: for example, in Yorkshire and the Humber infections fell by a quarter. This could be linked to tougher lockdown rules being introduced earlier in London and the south east after a surge in cases related to the more transmissible variant first discovered in Kent.

\section{Lifting lockdown}

The findings are based on 85473 swab tests taken from a representative sample of people aged 5 years and over from 4 to 13 February, in which 378 tested positive. The results are available as a preprint interim report and have not yet been peer reviewed.

Round 8 of the React study (mainly covering 6-21 January) indicated an initial plateau at the start of lockdown, followed by a decline towards the second half of that round. This latest round of the study found a strong decline since then.

Paul Elliott, director of the programme at Imperial College London, said, "These encouraging results show that lockdown measures are effectively bringing infections down. It's reassuring that the reduction in numbers of infections occurred in all ages and in most regions across the country."

Steven Riley, professor of infectious disease dynamics at Imperial, added, "The downward trend in the most recent React data is good news. If this can be maintained the pressure on the NHS will be greatly reduced, resulting in fewer hospital admissions and deaths."

Commenting on the results, Tom Wingfield, honorary consultant physician at Liverpool School of Tropical Medicine, said that the results should directly inform the precautions needed when lifting lockdown.

"Broadly speaking, reducing the prevalence of SARS-CoV-2 to as low a level as possible at the time of lifting lockdown measures will-alongside other measures such as suitable border control-provide the best environment for successful covid-19 control and potential mitigation of future covid-19 waves, including those related to new variants," he said.

Riley S, Walters C, Wang H, et al. REACT-1 round 9 interim report: downward trend of SARS-CoV-2 in England in February 2021 but still at high prevalence. 18 Feb 2021. https://spiral.imperial.ac.uk/handle/10044/1/86126.

This article is made freely available for use in accordance with BMJ's website terms and conditions for the duration of the covid-19 pandemic or until otherwise determined by BMJ. You may use, download and print the article for any lawful, non-commercial purpose (including text and data mining) provided that all copyright notices and trade marks are retained. 